\title{
Association between muscle atrophy/weakness and health care costs and utilization among patients receiving total knee replacement surgery: a retrospective cohort study
}

\author{
This article was published in the following Dove Press journal: \\ Journal of Pain Research \\ 31 July 2013 \\ Number of times this article has been viewed
}

\author{
Shih-Yin Chen' \\ Ning $\mathrm{Wu}^{\prime}$ \\ Yuan-Chi Lee' \\ Yang Zhao ${ }^{2}$ \\ 'Health Economics and Epidemiology, \\ Evidera, Lexington, Massachusetts, \\ USA; ${ }^{2}$ Health Economics and \\ Outcomes Research, Novartis \\ Pharmaceuticals Corporation, \\ East Hanover, New Jersey, USA
}

\begin{abstract}
Purpose: The aim of the study reported here was to examine health care resource utilization, costs, and risk of rehospitalization for total knee replacement (TKR) patients with and without muscle atrophy/weakness (MAW).

Patients and methods: Individuals aged 50-64 years with commercial insurance or 65+ years with Medicare Supplemental Insurance (Medicare) who had a hospitalization for TKR between January 1, 2006 and September 30, 2009 were identified from a large US claims database. First hospitalization for TKR was defined as the index stay. All patients were classified into three cohorts according to when MAW was diagnosed relative to TKR: pre-MAW, post-MAW, and no MAW. The association between MAW and health care costs over the 12-month post-index period and the probability of rehospitalization were assessed via multivariate regressions.

Results: The study sample included 53,696 Medicare and 46,058 commercial insurance TKR patients. Controlling for cross-cohort differences, both the pre- and post-MAW cohorts had significantly higher total health care costs (Medicare US\$4,201 and US\$9,404 higher, commercial insurance US\$2,737 and US\$6,640 higher, respectively) than the no MAW cohort (all $P<0.05)$. The post-MAW cohort in both populations was also more likely to have any all-cause or replacement-related rehospitalization compared with the no MAW cohort.

Conclusion: Among US patients undergoing TKR, those with MAW had higher health care utilization and costs than patients without MAW.
\end{abstract}

Keywords: rehospitalization, resource utilization, Medicare, health insurance, USA

\section{Introduction}

Total knee replacement (TKR) is one of the most common orthopedic surgeries performed in the USA. ${ }^{1}$ Most commonly, TKRs are performed as a result of the pain and decreased quality of life associated with osteoarthritis. ${ }^{2}$ As the US population ages and becomes more obese, ${ }^{3}$ it is expected that osteoarthritis rates, hence TKR rates, will continue to rise. TKRs have increased from 31.2 per 100,000 person-years in 1971-1975 to 220.9 in $2005-2008 .{ }^{4}$ The demand for primary TKR is projected to grow by sixfold to 3.48 million in $2030 .^{5}$ The high and rising incidence and prevalence of the TKR procedure in the USA indicates a large societal burden, especially for the Medicare program, since it has been estimated that $75 \%$ of all TKR cases in the USA are performed on Medicare beneficiaries. ${ }^{6}$ Knee replacements represented the most rapidly increasing hospital inpatient costs for all payers from 2002 to 2004, with a mean cost of US\$13,200 per admission and an aggregate cost of US\$6.3 billion during $2004 .^{7}$
Correspondence: Yang Zhao NJ 07936, USA

Tel + I 8627783662

Fax + I 973 78I 2390

Email yang-3.zhao@novartis.com 
While improvement of functioning is a goal of TKR, ${ }^{2}$ quadriceps muscle atrophy/weakness (MAW) is a common problem for TKR patients. ${ }^{8-13}$ MAW among these patients is typically the result of either muscle atrophy or the failure of voluntary muscle activation due to neurological impairment, ${ }^{8,9,11,13}$ and it has been shown to be associated with poorer functioning up to 2 years after the TKR. ${ }^{14}$ Previous studies have indicated that MAW exists among some TKR patients even before the TKR surgery ${ }^{8,9}$ and that patients are likely to have profound quadriceps MAW from 1 month $^{8}$ to 12 months $^{10}$ after the TKR procedure. However, as far as we are aware, no previous research has attempted to quantify the differences in health care resource use, costs, or other medical outcomes between TKR patients with and without MAW.

The retrospective, naturalistic study described here was designed to begin to quantify the burden of MAW among TKR patients. To this end, the main study objective was to examine differences of direct health care related costs and utilization in TKR patients between those with and without a diagnosis of MAW. The timing of the first MAW diagnosis recorded before or after the TKR surgery was also explored to assess its association with patient demographic, clinical, and economic characteristics.

\section{Methods}

This study utilized data between January 1, 2005 through September 30, 2010 from the Thomson Reuters MarketScan ${ }^{\circledR}$ Commercial Claims and Encounters (hereafter referred to as "Commercial") Database and the Medicare Supplemental Insurance (Medicare) Database. The databases include eligibility records and administrative claims from 33 million enrollees, 3 million of which are Medicare eligible, covered by approximately 100 self-insured payers. The databases contain information on enrollment status, health plan type, and demographic characteristics such as age, sex, and region of residence. Information captured on pharmacy claims includes National Drug Code, dispense date, quantity, days supplied, and plan- and patient-paid amounts. On the medical service claims, details of health service encounters such as date and place of service, provider type, plan- and patientpaid amounts, and International Classification of Diseases, 9th Revision, Clinical Modification (ICD-9-CM) diagnosis and procedure codes were recorded across all settings. These administrative claims databases are fully compliant with the Health Insurance Portability and Accountability Act of 1996 privacy requirements and can be used to track health care utilization and costs longitudinally using encrypted identifiers.
To be included in the study, a patient was required to have an inpatient stay with an associated procedure code of TKR (ICD-9-CM procedure code of 81.54 or Current Procedural Terminology code 27447) between January 1, 2006 and September 30, 2009. The admission date of the first such inpatient stay was denoted the index date. Patients who received a prior procedure of TKR during the period from 365 through 7 days prior to the index date were excluded. Patients were also required to have continuous insurance coverage from the 12 months before the index date (the pre-index period) through the 12 months after the discharge date recorded on the index hospital stay (the post-index period). Individuals in the Commercial database were required to be 50-64 years old at the index date, while those in the Medicare database were required to be at least 65 years old as of the index date. Patients in the Commercial and Medicare databases were analyzed separately, and each of these two populations was further subdivided into three distinct cohorts: those with no diagnosis of MAW (no MAW; ICD-9-CM 335.1x, 335.21, 359.xx, 728.2x, or 728.87) over the pre- and post-index periods, those diagnosed with MAW before TKR (pre-MAW), and those diagnosed with MAW during or after TKR (post-MAW).

The following study variables were examined:

- patient characteristics: age, sex, region of residence, type of insurance coverage, and comorbid osteoarthritis, rheumatoid arthritis, and osteoporosis

- overall burden of chronic disease, as assessed by the Charlson comorbidity index (CCI), which measures 23 different categories of comorbidities with a score that is used to predict health care costs ${ }^{15,16}$

- outcomes of interest related to the index hospitalization: length and cost of inpatient stay and discharge status (ie, discharge to a skilled nursing facility [SNF], home, inpatient rehabilitation facility, short-term hospital, other facility, and other alive status)

- health care resource use assessments: hospitalizations, physician office visits, outpatient hospital visits, emergency room (ER) visits, and the use of an SNF, inpatient rehabilitation facility, home health care, physical therapy, or occupational therapy.

Costs were calculated as total direct medical costs as well as inpatient, outpatient, and pharmacy costs. All costs were adjusted to 2011 US dollars using the medical care component of the Consumer Price Index (CPI). ${ }^{17}$

Descriptive analyses of the study variables were performed between the no MAW (as reference), pre-MAW, and post-MAW cohorts. Chi-square statistics were used to 
test differences for categorical variables (eg, sex, region of residence, health plan type, comorbidities, discharge status of index stay, and proportion with resource use). Student's $t$-test was utilized for between-group age differences, while nonparametric Wilcoxon rank-sum tests were utilized for CCI, length of index hospital stay, and pre-index and postindex health care resource utilization, and health care costs. Specific resource utilization variables assessed included total days in hospital, number of physician office visits, outpatient hospital visits, and ER visits.

Controlling for age, sex, region of residence, health plan type, comorbid osteoarthritis, rheumatoid arthritis, osteoporosis, CCI, pre-period resource use (any hospitalization, ER, or outpatient hospital visit), and discharge status from the index hospitalization, multivariate generalized linear regression models with log-link and gamma distribution were applied to assess the association between MAW and health care costs. The adjusted difference in health care costs for pre-MAW and post-MAW cohorts when compared with the no MAW cohort were estimated by calculating the expected mean change of health care costs as of a change in the MAW cohort variables while keeping all the other covariates constant. ${ }^{18}$ Two-part models were estimated to generate the adjusted differences in health care costs associated with $\mathrm{MAW}^{19}$ when at least $10 \%$ of the patients had zero costs. The probability of utilizing the service of interest was first estimated; in the second part, costs among those who utilized the service were estimated. The estimated costs were calculated as the predicted probability from the logistic regression (generated from the first part) multiplied by the expected cost conditional on having positive costs (from the second part). The adjusted difference in health care costs of pre- and post-MAW cohorts compared with the no MAW cohort was calculated as the mean difference among all individuals when their cohort variable was alternatively coded as " 0 " and " 1. ." A 95\% confidence interval (CI) was estimated using the 2.5 and 97.5 percentiles of the 1,000 estimated adjusted difference estimates by bootstrapping the two-part model with 1,000 iterations..$^{20}$ The difference was considered significant when the $95 \%$ CI did not include zero.

Logistic regressions were employed to examine the impact of MAW on the probability of having an all-cause or replacement-related rehospitalization in the post-index period. The explanatory variables included MAW cohorts, age, sex, region of residence, health plan type, CCI, comorbid osteoarthritis, rheumatoid arthritis, osteoporosis, discharge status from the index hospitalization, and pre-index any hospitalization, ER, or outpatient hospital visit. Both the odds ratios (ORs) and the $95 \% \mathrm{CI}$ were reported. All analyses were performed using SAS (v 9.1; SAS Institute Inc, Cary, NC, USA) and $P$-values $<0.05$ were considered, a priori, statistically significant.

\section{Results}

This study included 53,696 patients aged 50-64 years in the Commercial population and 46,058 patients aged 65 or older in the Medicare population (Table 1). In the Commercial population, the prevalence of MAW prior to the TKR (pre-MAW) was $0.9 \%$ and during or after the TKR (post-MAW) was $4.6 \%$. MAW was found to be present in approximately the same proportion in the Medicare population, with $1.1 \%$ of individuals in the pre-MAW and $4.2 \%$ in the post-MAW cohorts. The mean age was approximately 58 years for the Commercial population and 75 years for the Medicare population. Approximately $63 \%$ of the study population was female. The majority of the patients in the Commercial population lived in the South region, and were members of a preferred provider organization health plan. In contrast, the majority of the Medicare population lived in the Midwest region and belonged to a comprehensive health plan. Prevalence of osteoarthritis was high, with over $95 \%$ of the study population affected, and this is likely to be the main reason for TKR. The average length of stay of the index hospitalization ranged from 3.5 to 4.0 days across cohorts. However, total costs associated with the index hospitalization were higher for the Commercial population than for the Medicare population ( $\sim$ US $\$ 28,000$ vs $\sim \mathrm{US} \$ 20,000$ ). A higher proportion of patients from the Commercial population was discharged to home than from the Medicare population ( $\sim 80 \%$ vs $\sim 65 \%$ ). Several cross-cohort differences were observed. In the Medicare population, pre- and post-MAW cohorts were significantly older, had a higher CCI score, and were more likely to have comorbid osteoarthritis; they also had higher index hospitalization costs and a longer index hospital stay than the no MAW cohort. The pre- and post-MAW cohorts in the Commercial population were more likely to be female and to have comorbid osteoporosis, and a higher CCI score.

Table 2 summarizes the health care utilization during the pre- and post-index periods. For both insurance populations (Commercial and Medicare), patients in the pre- or postMAW cohorts in general had significantly higher health care utilization, including more visits to the physician office and ER and a significantly greater likelihood of an outpatient hospital or an ER visit in both the pre- and post-index periods than the no MAW cohort. The post-MAW cohort also had a higher rate of hospitalization in both the pre- and post-index 
Table I Patient characteristics

\begin{tabular}{|c|c|c|c|c|c|c|}
\hline & \multicolumn{3}{|l|}{ Commercial } & \multicolumn{3}{|l|}{ Medicare } \\
\hline & Pre-MAW & Post-MAW & No MAW & Pre-MAW & Post-MAW & No MAW \\
\hline $\mathrm{N}, \%$ & $470(0.9)$ & $2,742(4.6)$ & $50,484(94.0)$ & $508(I . I)$ & $1,939(4.2)$ & $43,611(94.7)$ \\
\hline \multicolumn{7}{|l|}{ Demographics } \\
\hline Age in years, mean (SD) & $58.5(3.8)$ & $58.2(3.9)$ & $58.3(3.8)$ & $76.2^{*}(6.0)$ & $76.0 *(6.1)$ & $74.9(5.7)$ \\
\hline Sex, $\%$ & $*$ & $*$ & & & & \\
\hline Male & 31.9 & 35.4 & 37.3 & 33.9 & 36.0 & 37.8 \\
\hline Female & 68.1 & 64.6 & 62.8 & 66.1 & 64.0 & 62.2 \\
\hline Region, \% & $*$ & $*$ & & & & \\
\hline Northeast & 5.3 & 5.1 & 8.1 & 6.1 & 8.6 & 8.6 \\
\hline Midwest & 38.1 & 31.5 & 33.1 & 45.9 & 41.2 & 41.0 \\
\hline South & 48.1 & 53.1 & 45.1 & 29.9 & 32.7 & 31.2 \\
\hline West & 8.1 & 9.8 & 13.2 & 17.1 & 16.9 & 18.3 \\
\hline Unknown & 0.4 & 0.5 & 0.5 & 1.0 & 0.7 & 0.9 \\
\hline Health plan, \% & $*$ & $*$ & & $*$ & $*$ & \\
\hline PPO & 64.9 & 67.3 & 59.3 & 33.5 & 31.5 & 27.9 \\
\hline Comprehensive & 14.5 & 10.5 & 11.7 & 59.1 & 59.6 & 60.6 \\
\hline $\mathrm{HMO}$ & 8.5 & 9.9 & I4.I & 4.3 & 5.6 & 8.3 \\
\hline Other & 11.3 & 10.8 & 13.3 & 1.6 & 1.5 & 1.7 \\
\hline Missing & 0.9 & 1.4 & 1.6 & 1.6 & 1.8 & 1.5 \\
\hline \multicolumn{7}{|c|}{ Pre-index period comorbidities } \\
\hline Charlson score, mean (SD) & $5.9 *(4.3)$ & $5.0 *(3.8)$ & $4.6(3.7)$ & $6.8^{*}(4.2)$ & $5.8^{*}(3.8)$ & $5.2(3.7)$ \\
\hline Osteoarthritis, \% & 98.1 & 97.1 & 96.8 & $98.8^{*}$ & $96.9 *$ & 95.1 \\
\hline Osteoporosis, \% & $20.4 *$ & $12.1 *$ & 10.7 & $22.8^{*}$ & 17.9 & 14.0 \\
\hline Rheumatoid arthritis, \% & $7.2^{*}$ & 4. 7 & 4.3 & $5.5^{*}$ & 3.6 & 3.1 \\
\hline \multicolumn{7}{|l|}{ Index hospitalization } \\
\hline Length of stay (days), mean (SD) & $3.7(2.2)$ & $3.6 *(2.1)$ & $3.5(1.9)$ & $3.9 *(2.6)$ & $4.0 *(3.9)$ & $3.6(2.0)$ \\
\hline $\begin{array}{l}\text { Cost of inpatient stay in US\$, } \\
\text { mean (SD) }\end{array}$ & $28,027(15,336)$ & $29,386 *(15,192)$ & $28,209(15,304)$ & $22,533 *(20,43 I)$ & $22,350 *(20,089)$ & $20,365(26,120)$ \\
\hline Discharge status, $\%$ & $*$ & * & & $*$ & $*$ & \\
\hline Home & 75.3 & 77.0 & 79.8 & 54.1 & 50.8 & 65.6 \\
\hline Skilled nursing facility & 8.3 & 9.8 & 6.4 & 22.8 & 22.6 & 14.4 \\
\hline Inpatient rehabilitation facility & 7.0 & 4.3 & 3.5 & 5.7 & 6.2 & 4.9 \\
\hline Short-term hospital & 2.8 & 2.7 & 1.6 & 9.8 & 14.0 & 8.4 \\
\hline Other facility & 0.9 & 1.3 & 1.5 & 2.2 & 2.1 & 1.2 \\
\hline Other alive status & 5.7 & 4.9 & 7.2 & 5.3 & 4.3 & 5.5 \\
\hline
\end{tabular}

Note: $* P<0.05$ compared with the no MAW cohort.

Abbreviations: HMO, health maintenance organization; MAW, muscle atrophy/weakness; PPO, preferred provider organization; SD, standard deviation.

periods, while a higher rate of hospitalization was only observed in the pre-index period for the pre-MAW cohort when compared with the no MAW cohort. In addition, relative to the no MAW cohort, the pre- and post-MAW cohorts were more likely to have used an SNF or to have received an occupational therapy in the post-period.

The unadjusted health care costs in the pre- and postindex periods for each cohort are summarized in Table 3. In both the Commercial and Medicare populations, the preand post-MAW cohorts had higher costs than the no MAW cohort, except for the post-MAW cohort in the Commercial population. Nearly half of the costs resulted from outpatient services. In the post-index period, both the pre- and postMAW patients had significantly higher total health care costs than the no MAW patients (Commercial, US\$26,965 pre-
MAW and US\$27,521 post-MAW vs US\$19,814 no MAW; Medicare, US\$24,081 pre-MAW and US\$27,663 post-MAW vs US $\$ 16,539$ no MAW; all $P<0.05$ ). Total costs increased from the pre- to the post-index period the most for the postMAW cohort, followed by the no MAW cohort but remained similar for the pre-MAW cohort.

The impact of MAW on direct health care costs, controlling for cross-cohort differences, is presented in Figure 1. Among the Commercial patients, those in the pre- and post-MAW cohorts had significantly higher adjusted total costs than the no MAW cohort (cost difference, US $\$ 2,737$ pre-MAW and US\$6,640 post-MAW; both $P<0.05$ ). Similarly, the Medicare patients in the pre-MAW and post-MAW cohorts had significantly higher total adjusted costs than the no MAW cohort (US\$4,201 pre-MAW and US\$9,404 
Table 2 Health care resource utilization over the 12-month pre- and post-index periods

\begin{tabular}{|c|c|c|c|c|c|c|}
\hline & \multicolumn{3}{|c|}{ Commercial } & \multicolumn{3}{|l|}{ Medicare } \\
\hline & Pre-MAW & Post-MAW & No MAW & Pre-MAW & Post-MAW & No MAW \\
\hline \multicolumn{7}{|l|}{ Pre-index period } \\
\hline Hospital stay, \% & $24.9 *$ & $10.4 *$ & 9.1 & $35.4 *$ & $15.7^{*}$ & 13.2 \\
\hline Total hospital days, mean (SD) & $2.1 *(6.1)$ & $0.4^{*}(2.0)$ & $0.4(2.2)$ & $2.1 *(5.2)$ & $0.7^{*}(2.9)$ & $0.5(2.1)$ \\
\hline Physician office visits, $\%$ & 99.8 & 99.6 & 99.6 & 99.4 & $99.5^{*}$ & 99.0 \\
\hline $\begin{array}{l}\text { Number of physician office visits, } \\
\text { mean (SD) }\end{array}$ & $28.8^{*}(19.3)$ & $18.2 *(13.9)$ & I7.I (13.I) & $28.1 *(16.9)$ & $20.2 *(13.4)$ & $17.6(12.3)$ \\
\hline Outpatient hospital visits, \% & $96.2^{*}$ & $89.1^{*}$ & 87.7 & $95.5^{*}$ & $92.0^{*}$ & 87.9 \\
\hline $\begin{array}{l}\text { Number of outpatient hospital } \\
\text { visits, mean (SD) }\end{array}$ & $7.9 *(8.1)$ & $4.4(5.9)$ & $4.3(5.4)$ & $8.3 *(10.0)$ & $5.4^{*}(6.5)$ & $4.4(5.8)$ \\
\hline Emergency room visits, \% & $31.9 *$ & $23.7^{*}$ & 21.5 & $34.8^{*}$ & $25.7^{*}$ & 19.3 \\
\hline $\begin{array}{l}\text { Number of emergency room } \\
\text { visits, mean (SD) }\end{array}$ & $0.5^{*}(1.2)$ & $0.4^{*}(1.0)$ & $0.3(1.0)$ & $0.7 *(1.3)$ & $0.4^{*}(\mathrm{I} . \mathrm{I})$ & $0.3(0.8)$ \\
\hline \multicolumn{7}{|l|}{ Post-index period } \\
\hline Hospital stay, \% & 25.7 & $29.9 *$ & 22.6 & 23.0 & $33.5^{*}$ & 21.3 \\
\hline Total hospital days, mean (SD) & $2.0 *(6.2)$ & $2.3^{*}(7.6)$ & I.I (3.8) & $1.6(6.2)$ & $2.7^{*}(7.9)$ & $1.0(3.8)$ \\
\hline Physician office visits, \% & 99.6 & $99.8^{*}$ & 99.4 & 99.0 & $99.7^{*}$ & 98.6 \\
\hline $\begin{array}{l}\text { Number of physician office visits, } \\
\text { mean (SD) }\end{array}$ & $30.3^{*}(21.5)$ & $27.6 *(19.9)$ & $24.6(18.4)$ & $28.7^{*}(19.6)$ & $28.5^{*}(19.1)$ & $22.8(16.7)$ \\
\hline Outpatient hospital visits, \% & $88.3 *$ & $85.5^{*}$ & 83.3 & $89.8^{*}$ & $90.8^{*}$ & 82.5 \\
\hline $\begin{array}{l}\text { Number of outpatient hospital } \\
\text { visits, mean (SD) }\end{array}$ & $8.7^{*}(10.5)$ & $8.4^{*}(11.2)$ & $7.7(10.5)$ & $8.5^{*}(11.8)$ & $9.1 *(12.0)$ & $6.0(8.6)$ \\
\hline Emergency room visits, \% & $30.0 *$ & $26.6^{*}$ & 21.4 & $32.1 *$ & $37.1^{*}$ & 23.0 \\
\hline $\begin{array}{l}\text { Number of emergency room } \\
\text { visits, mean (SD) }\end{array}$ & $0.5^{*}(1.1)$ & $0.5^{*}(1.3)$ & $0.4(1.1)$ & $0.6 *(1.0)$ & $0.8^{*}(1.7)$ & $0.4(0.9)$ \\
\hline Skilled nursing facility stay, \% & $14.9 *$ & $16.5^{*}$ & 10.2 & $36.0^{*}$ & $43.7^{*}$ & 23.9 \\
\hline Inpatient rehabilitation stay, \% & $7.7^{*}$ & $5.4^{*}$ & 4.5 & 0.8 & $1.9 *$ & 0.8 \\
\hline Home health visit, \% & 3.2 & $3.7^{*}$ & 2.9 & $1.8^{*}$ & $1.6 *$ & 0.6 \\
\hline Physical therapy, \% & 81.1 & $85.0 *$ & 80.5 & $59.7^{*}$ & $64.1 *$ & 53.1 \\
\hline Occupational therapy, \% & $24.7 *$ & $25.2^{*}$ & 20.4 & $19.1^{*}$ & $20.4^{*}$ & 14.0 \\
\hline
\end{tabular}

Note: $* P<0.05$ compared with the no MAW cohort.

Abbreviations: MAW, muscle atrophy/weakness; SD, standard deviation.

post-MAW; both $P<0.05)$. Outpatient costs appeared to be the largest contributor of cost differences in the Medicare pre-MAW, post-MAW, and Commercial pre-MAW cohorts, while the Commercial post-MAW cohort had inpatient costs as the major contributor.
Post-MAW was associated with a significantly higher likelihood of being rehospitalized during the post-index period (Table 4). Specifically, compared with the no MAW patients, the post-MAW patients had a 44\% higher likelihood of being rehospitalized for any cause $(\mathrm{OR}=1.44$;

Table 3 Unadjusted health care costs over the 12-month pre- and post-index periods

\begin{tabular}{|c|c|c|c|c|c|c|}
\hline & \multicolumn{3}{|l|}{ Commercial } & \multicolumn{3}{|l|}{ Medicare } \\
\hline & Pre-MAW & Post-MAW & No MAW & Pre-MAW & Post-MAW & No MAW \\
\hline \multicolumn{7}{|c|}{ Pre-index period costs in US\$, mean (SD) } \\
\hline Inpatient & $8,236 *(21,306)$ & $2,114 *(9,906)$ & $2,015(11,016)$ & $7,748 *(19,686)$ & $2,652 *(12,764)$ & $2,048(9,255)$ \\
\hline Outpatient & $15,702 *(17,254)$ & $8,502 *(10,430)$ & $7,897(10,390)$ & $12,985 *(|5,29|)$ & $8,278^{*}(11,353)$ & $6,922(15,596)$ \\
\hline Pharmacy & $3,633 *(5,911)$ & $2,515 *(4,059)$ & $2,691(4,356)$ & $4,602 *(4,464)$ & $4,109 *(4,539)$ & $3,577(3,666)$ \\
\hline Total & $27,57 \mid *(32,76 I)$ & $|3| 3 \mid,(|7,5| 2)$ & $12,602(17,786)$ & $25,335 *(30,047)$ & $15,039 *(21,357)$ & $12,547(19,807)$ \\
\hline \multicolumn{7}{|c|}{ Post-index period costs in US\$, mean (SD) } \\
\hline Inpatient & $8,653 *(21,072)$ & $12,097 *(30,609)$ & $6,924(20,198)$ & $5,161(12,109)$ & $8,405^{*}(22,723)$ & $4,465(16,078)$ \\
\hline Outpatient & $14,553 *(2|| 10)$, & $|2,7| 6 *(|7.40|)$ & $10,046(12,160)$ & $\mid 4,398 *(|7,8| 7)$ & $15,395 *(19,276)$ & $8,588(12,023)$ \\
\hline Pharmacy & $3,759 *(5,643)$ & $2,708 *(4,298)$ & $2,845(4,939)$ & $4,522 *(4,5 \mid 4)$ & $3,863 *(4,29 I)$ & $3,486(3,716)$ \\
\hline Total & $26,965 *(36,536)$ & $27,52 I *(40,884)$ & $19,8 \mid 4(27,596)$ & $24,08 I *(24,838)$ & $27,663 *(34,768)$ & $16,539(23,116)$ \\
\hline
\end{tabular}

Note: $* P<0.05$ compared with the no MAW cohort.

Abbreviations: MAW, muscle atrophy/weakness; SD, standard deviation. 
A

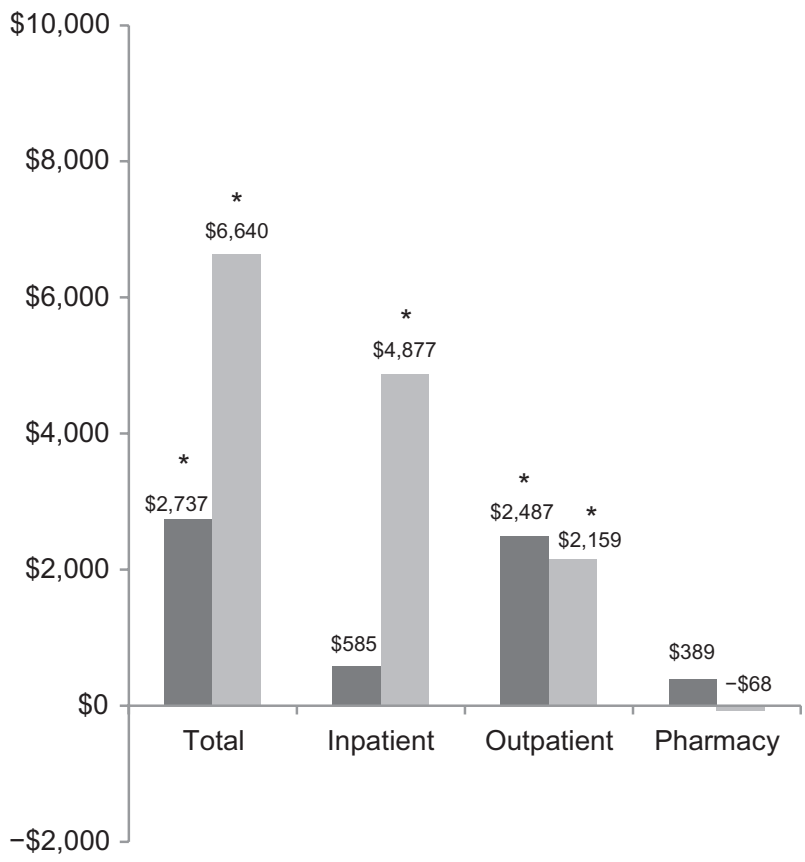

- Pre-MAW vs No MAW Post-MAW vs No MAW
B

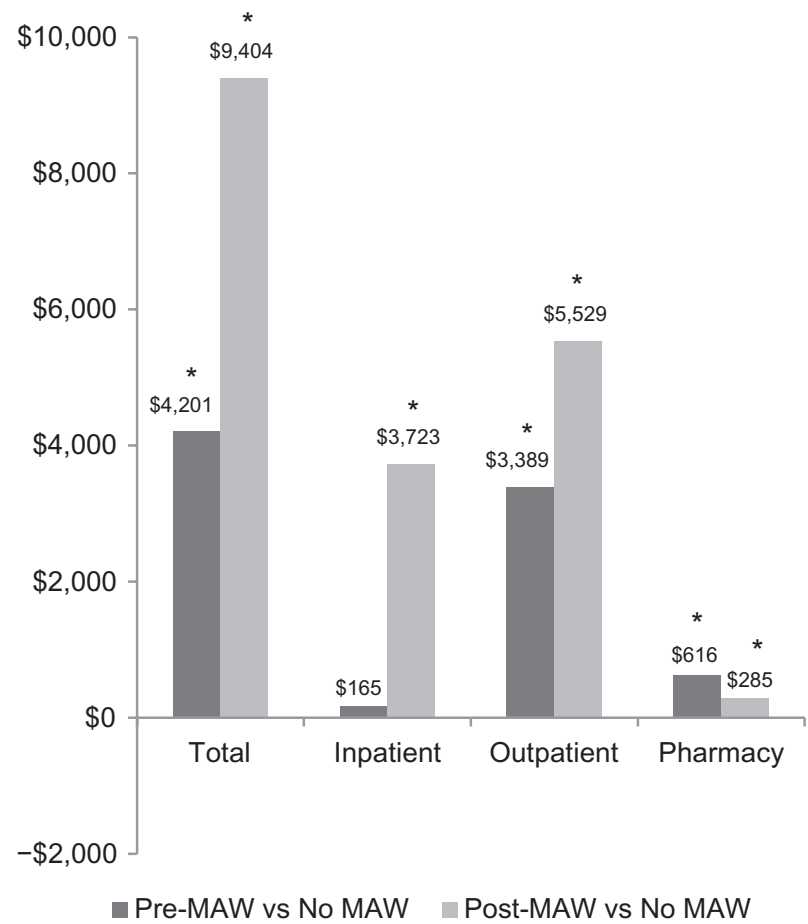

Figure I Adjusted difference in health care costs in US dollars: (A) Commercial; (B) Medicare.

Notes: Marginal differences for total, outpatient, and Medicare population pharmacy costs were calculated by generalized linear regression models, adjusting for age, sex, region of residence, health plan type, related comorbidities, discharge status, and pre-index resource use. Marginal differences for inpatient costs in both populations and pharmacy costs in commercial population were calculated by two-part models due to excessive zero costs. *P $<0.05$ compared with the no MAW cohort.

Abbreviation: MAW, muscle atrophy/weakness.

Table 4 Factors associated with hospitalization over the I2-month post-index period ${ }^{\mathrm{a}}$

\begin{tabular}{|c|c|c|c|c|c|c|c|c|}
\hline & \multicolumn{4}{|c|}{ Commercial } & \multicolumn{4}{|c|}{ Medicare } \\
\hline & \multicolumn{2}{|c|}{ All cause } & \multicolumn{2}{|c|}{$\begin{array}{l}\text { Replacement } \\
\text { related }\end{array}$} & \multicolumn{2}{|c|}{ All cause } & \multicolumn{2}{|c|}{$\begin{array}{l}\text { Replacement } \\
\text { related }\end{array}$} \\
\hline & OR & $95 \% \mathrm{Cl}$ & OR & $95 \% \mathrm{Cl}$ & OR & $95 \% \mathrm{Cl}$ & OR & $95 \% \mathrm{Cl}$ \\
\hline \multicolumn{9}{|l|}{ MAW' } \\
\hline Pre-MAW & 1.02 & $0.83-1.26$ & $1.74 *$ & $1.05-2.90$ & 0.93 & $0.75-1.15$ & 1.35 & $0.60-3.05$ \\
\hline Post-MAW & $1.44 *$ & $1.32-1.57$ & $2.10^{*}$ & $1.70-2.60$ & $\mathrm{I} .79 *$ & $1.62-1.97$ & $2.06 *$ & $1.43-2.97$ \\
\hline \multicolumn{9}{|l|}{ Charlson score $^{c}$} \\
\hline I & $1.12 *$ & $1.03-1.21$ & $1.30 *$ & $1.02-1.65$ & $1.18 *$ & $1.08-1.29$ & 0.89 & $0.58-1.36$ \\
\hline 2 or 3 & $\mathrm{I} .33 *$ & $1.21-1.46$ & $1.67 *$ & $1.28-2.17$ & $1.23 *$ & $1.12-1.35$ & 1.27 & $0.84-1.92$ \\
\hline $4+$ & $1.29 *$ & $1.22-1.35$ & $1.21 *$ & $1.03-1.42$ & $1.23 *$ & $1.15-1.30$ & 1.18 & $0.90-1.56$ \\
\hline \multicolumn{9}{|l|}{ Select comorbidities } \\
\hline Osteoarthritis & I.II & $0.98-1.25$ & $0.63^{*}$ & $0.47-0.85$ & 1.10 & $0.99-1.23$ & 1.26 & $0.75-2.12$ \\
\hline Rheumatoid arthritis & $1.28 *$ & $|| 7-.|.4|$ & 1.26 & $0.96-1.66$ & $1.35 *$ & $1.20-1.52$ & 1.13 & $0.67-1.90$ \\
\hline Osteoporosis & 1.01 & $0.95-1.08$ & 1.20 & $0.99-1.45$ & 1.00 & $0.94-1.07$ & 1.21 & $0.92-1.61$ \\
\hline \multicolumn{9}{|l|}{ Discharge status $^{\mathrm{d}}$} \\
\hline Skilled nursing facility & $\mathrm{I} .19 *$ & $1.10-1.29$ & $1.16^{*}$ & $0.91-1.48$ & $\mathrm{I} .17^{*}$ & $\mathrm{I} .10-1.24$ & 1.00 & $0.75-1.33$ \\
\hline Other facility & $1.4 I^{*}$ & $1.20-1.65$ & 1.22 & $0.73-2.03$ & 1.07 & $0.88-1.31$ & 0.19 & $0.03-1.39$ \\
\hline Other alive status & 1.01 & $0.93-1.09$ & 1.09 & $0.86-1.40$ & 1.05 & $0.95-1.16$ & 0.82 & $0.49-1.35$ \\
\hline Inpatient rehabilitation facility & $1.61 *$ & $1.46-1.78$ & $1.38 *$ & $1.03-1.86$ & 1.07 & $0.97-1.19$ & 1.04 & $0.66-1.64$ \\
\hline \multicolumn{9}{|l|}{ Pre-index utilization } \\
\hline Hospitalization & $\mathrm{I} .57 *$ & $1.47-1.68$ & $1.53 *$ & $1.28-1.84$ & $\mathrm{I} .57 *$ & $1.47-1.66$ & $1.44^{*}$ & $1.1 \mathrm{I}-\mathrm{I} .87$ \\
\hline Outpatient service & $1.10 *$ & $1.03-1.18$ & $\mathrm{I} .48^{*}$ & I.I7-I.87 & 0.98 & $0.91-1.05$ & 0.80 & $0.59-1.10$ \\
\hline Emergency room visit & $1.16 *$ & $1.11-1.22$ & $1.16^{*}$ & $1.00-1.35$ & $1.16 *$ & $1.10-1.23$ & 1.27 & $1.00-1.62$ \\
\hline
\end{tabular}

Notes: ${ }^{a}$ Results from logistic regressions were also adjusted for age, sex, region of residence, and health plan type; ${ }^{b}$ reference category, no MAW; ${ }^{~}$ reference category,

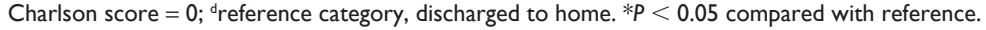

Abbreviations: $\mathrm{Cl}$, confidence interval; MAW, muscle atrophy/weakness; OR, odds ratio. 
95\% CI: $1.32-1.57$ ) and a 110\% higher likelihood of a replacement-related rehospitalization $(\mathrm{OR}=2.10 ; 95 \% \mathrm{CI}$ : 1.70-2.60) among the Commercial population. Similarly, Medicare patients in the post-MAW cohort were found to be 1.79 times more likely to be rehospitalized for any cause $(\mathrm{OR}=1.79 ; 95 \% \mathrm{CI}: 1.62-1.97)$ and 2.06 times more likely to have a replacement-related rehospitalization $(\mathrm{OR}=2.06$; 95\% CI: 1.43-2.97) compared with those in the no MAW cohort. Patients in the pre-MAW cohort were associated with a higher risk of replacement-related rehospitalization $(\mathrm{OR}=1.74,95 \% \mathrm{CI}: 1.05-2.90)$ in the Commercial population when compared with those in the no MAW cohort. Other factors associated with a significantly higher likelihood of rehospitalization for any cause included a higher CCI score, a diagnosis of rheumatoid arthritis, a discharge to an SNF, or a hospitalization or ER visit during the preindex period.

\section{Discussion}

The rate of TKR in the USA is projected to increase as the population ages and becomes more obese. ${ }^{5}$ The introduction of newer technologies that improve implant longevity in younger and more active patients has allowed the use of TKR in this younger and more active population. It has been estimated that the demand for primary TKR among patients less than 65 years old will exceed $50 \%$ by $2016 .{ }^{21}$ With the increasing burden of TKR on both Commercial health plans as well as the Medicare program due to an aging population, it is thus important to understand the resource utilization and costs associated with the procedure, and to identify the highcost patients. To the best of our knowledge, this study is the first to compare the health care resource use, costs, and risk of rehospitalization among TKR patients with and without MAW and our results have confirmed our hypothesis that MAW is associated with more health care resource utilization and costs in patients receiving TKR.

Similar to findings from previous publications on TKR, TKR was found to be more commonly performed in females, ${ }^{22,23}$ over $94 \%$ of the patients had osteoarthritis, ${ }^{23}$ and close to a quarter of patients had hospitalizations after the TKR. ${ }^{24}$ The average length of stay for TKR was shorter in this study ( $\sim 3.5$ days) than that reported in previous studies (4.9 and 4.3 days). ${ }^{22,23}$ The shorter hospital stay is not surprising, as post-surgery care has been shifted to rehabilitation over time. ${ }^{24}$ Total costs associated with TKR hospitalization have been reported between US\$9,989 and US $\$ 10,067,,^{23}$ lower than the costs estimated in this study (Commercial, US\$28,268; Medicare, US\$20,445). The costs in the Bastis et al study were adjusted to 2005 US dollars, while costs were adjusted to 2011 US dollars in this study. Medical cost inflation may at least partially account for the differences. ${ }^{17}$ Additionally, the Bastis et al study examined costs from a health care provider perspective rather than the payer perspective as shown in the current study.

As far as we are aware, this study is the first to have investigated the burden associated with MAW among patients undergoing TKR. Patients with MAW had higher health care utilization and costs than those without MAW. While early research on MAW among TKR patients is limited, the findings of higher costs and health care resource use from the present analysis support a small observational study indicating pre-MAW to be a predictor of poorer post-surgical functioning (greater likelihood of requiring a handrail to negotiate stairs) 2 years after the TKR. ${ }^{14}$ It should be noted, however, that this earlier study focused only on TKR patients with end-stage knee osteoarthritis, while the present study includes TKR patients with pre-index period, less severe osteoarthritis and musculoskeletal conditions other than osteoarthritis (eg, osteoporosis and rheumatoid arthritis). By documenting the impact of MAW on health care costs and utilization associated with TKR, the present research provides relevant and important information to health care providers, payers, and TKR patients when evaluating and preparing for the surgery. The findings from this study demonstrate that the presence of MAW is a key cost driver in this population undergoing TKR. Proper prevention and/or management of MAW may result in cost saving. Future studies should aim at identifying the patients at risk of MAW.

In addition to being costly before TKR, pre-MAW patients remained costly after their surgery. This finding is consistent with previous research reporting that pre-existing MAW is likely to persist and, indeed, to worsen after TKR. ${ }^{10,12}$ Patients developing MAW during or after TKR had the greatest increase in health care costs, followed by patients with no MAW, over the 12 months post-surgery. This result is in agreement with previous clinical research showing that the average TKR patient is likely to experience an approximately $60 \%$ reduction in quadriceps strength after surgery $;{ }^{8,9,13}$ such a profound decrease in strength would logically increase a patient's use of medical resources, which, in turn, would lead to higher direct costs. In contrast, the total costs remained unchanged from the 12-month pre-index period to the post-index period for patients in the pre-MAW cohort. Further studies may need to examine why the costs changed differently for different types of TKR patients after the surgery, and whether there are interventions or proper 
management that can help prevent MAW during or after TKR surgery.

\section{Limitations}

This study has several limitations. The identification of MAW was solely based on diagnostic codes; therefore, MAW patients might be misclassified if the diagnosis was not recorded on the claims. The analysis focused exclusively on patients with medical and prescription benefit coverage, and the findings may not be generalizable to other populations. Similarly, since we excluded patients who had a prior knee replacement procedure in the previous year and patients without continuous eligibility during the 12-month pre-index or post-index period, the findings are not generalizable to those who had a second surgery or those who died within a year post-surgery. Further, the use of medical claims data precludes the assessment of quality-of-life outcomes, indirect costs, or medical services paid solely out-of-pocket. Unobservable confounders might have biased the estimates. As a result, the findings from this analysis can only be interpreted as association, not causation.

\section{Conclusion}

This analysis of patients with TKR showed that those with MAW had a greater burden of health care resource use and costs as compared with patients without MAW. Strategies targeting these high-cost patients may be considered to lessen the economic burden associated with this patient population.

\section{Acknowledgments}

This study was funded by Eli Lilly and Company. The authors would like to thank HealthMetrics Outcomes Research for writing assistance.

\section{Authors' contributions}

SYC and NW participated in study design, acquisition of data, analysis and interpretation of data, and drafting and revising the manuscript. YCL was involved in the analysis and interpretation of data, and critically revised the manuscript. YZ made signification contributions to the study conception and design, interpretation of data, critically drafting and revising the manuscript, and providing final approval for publication. All authors read and approved the final version of the manuscript for publication.

\section{Disclosure}

YZ was an employee of Eli Lilly and Company and owned company stock when this study was carried out. SYC, YCL, and NW are employed by Evidera, which provides consulting and other research services to pharmaceutical, device, government, and non-government organizations. In their salaried positions, they work with a variety of companies and organizations and are precluded from receiving payment or honoraria directly from these organizations for services rendered. The authors declare no other conflicts of interest in this work.

\section{References}

1. National Center for Health Statistics, Centers for Disease Control and Prevention, US Department of Health and Human Services. Health, United States, 2009: with Special Feature on Medical Technology. Hyattsville, MD: National Center for Health Statistics; 2010. Available from: http://www.cdc.gov/nchs/data/hus/hus09.pdf. Accessed June 17, 2013.

2. Carr AJ, Robertsson O, Graves S, et al. Knee replacement. Lancet. 2012;379:1331-1340.

3. Wilson NA, Schneller ES, Montgomery K, Bozic KJ. Hip and knee implants: current trends and policy considerations. Health Affairs. 2008;27(6):1587-1598.

4. Singh JA, Vessely MB, Harmsen WS, et al. A population-based study of trends in the use of total hip and total knee arthroplasty, 1969-2008. Mayo Clin Proc. 2010;85(10):898-904.

5. Kurtz S, Ong K, Lau E, Mowat F, Halpern M. Projections of primary and revision hip and knee arthroplasty in the United States from 2005 to 2030. J Bone Joint Surg Am. 2007;89(4):780-785.

6. Katz BP, Freund DA, Heck DA, et al. Demographic variation in the rate of knee replacement: a multi-year analysis. Health Serv Res. 1996;31(2): 125-140.

7. Merrill, C. (Thomson Healthcare) and Elixhauser, A. (AHRQ). Hospital Stays Involving Musculoskeletal Procedures, 1997-2005. HCUP Statistical Brief \#34. July 2007. Agency for Healthcare Research and Quality, Rockville, MD. Available from: http://www.hcup-us.ahrq.gov/ reports/statbriefs/sb34.pdf.

8. Mizner RL, Petterson SC, Stevens JE, Vandenborne K, SnyderMackler L. Early quadriceps strength loss after total knee arthroplasty. The contributions of muscle atrophy and failure of voluntary muscle activation. J Bone Joint Surg Am. 2005;87(5):1047-1053.

9. Mizner RL, Stevens JE, Snyder-Mackler L. Voluntary activation and decreased force production of the quadriceps femoris muscle after total knee arthroplasty. Phys Ther. 2003;83(4):359-365.

10. Petterson SC, Mizner RL, Stevens JE, et al. Improved function from progressive strengthening interventions after total knee arthroplasty: a randomized clinical trial with an imbedded prospective cohort. Arthritis Rheum. 2009;61(2):174-183.

11. Petterson SC, Barrance P, Marmon AR, Handling T, Buchanan TS, Snyder-Mackler L. Time course of quad strength, area, and activation after knee arthroplasty and strength training. Med Sci Sports Exerc. 2011;43(2):225-231.

12. Petterson S, Snyder-Mackler L. The use of neuromuscular electrical stimulation to improve activation deficits in a patient with chronic quadriceps strength impairments following total knee arthroplasty. J Orthop Sports Phys Ther. 2006;36(9):678-685.

13. Stevens JE, Mizner RL, Snyder-Mackler L. Quadriceps strength and volitional activation before and after total knee arthroplasty for osteoarthritis. J Orthop Res. 2003;21(5):775-779.

14. Zeni JA Jr, Snyder-Mackler L. Preoperative predictors of persistent impairments during stair ascent and descent after total knee arthroplasty. J Bone Joint Surg Am. 2010;92(5):1130-1136.

15. Charlson ME, Charlson RE, Peterson JC, Marinopoulos SS, Briggs WM, Hollenberg JP. The Charlson comorbidity index is adapted to predict costs of chronic disease in primary care patients. J Clin Epidemiol. 2008;61(12):1234-1240. 
16. Deyo RA, Cherkin DC, Ciol MA. Adapting a clinical comorbidity index for use with ICD-9-CM administrative databases. J Clin Epidemiol. 1992;45(6):613-619.

17. US Bureau of Labor Statistics. Databases, tables and calculators by subject: Inflation and prices [web page on the Internet linking to individual tools]. Washington DC: US Bureau of Labor Statistics; nd. Available from: http://www.bls.gov/data/\#prices. Accessed July 17, 2013.

18. Greene WH. Econometric Analysis. Pearson Education, Inc., Upper Saddle River, New Jersey, USA. 5th ed. Prentice Hall; 2002.

19. Afifi AA, Kotlerman JB, Ettner SL, Cowan M. Methods for improving regression analysis for skewed continuous or counted responses. Ann Rev Public Health. 2007;28:95-111.

20. Efron B, Tibshirani R. An Introduction to the Bootstrap. Boca Raton, FL: Chapman and Hall/CRC Press; 1993.

21. Kurtz SM, Lau E, Ong K, Zhao K, Kelly M, Bozic KJ. Future young patient demand for primary and revision joint replacement: national projections from 2010 to 2030. Clin Orthop Relat Res. 2009;467(10): 2606-2612.
22. Crawford DA, Scully W, McFadden L, Manoso M. Preoperative predictors of length of hospital stay and discharge disposition following primary total knee arthroplasty at a military medical center. Mil Med. 2011;176(3):304-307.

23. Bastis JA, Naessens JM, Keegan MT, Huddleston PM, Wagie AE, Huddleston JM. Resource utilization of total knee arthroplasty patients cared for on specialty orthopedic surgery units. Journal of Hospital Medicine. 2008;3(3):218-227.

24. Singh JA, Sloan J. Higher comorbidity, poor functional status and higher health care utilization in veterans with prevalent total knee arthroplasty or total hip arthroplasty. Clin Rheumatol. 2009;28(9): 1025-1033.
Journal of Pain Research

\section{Publish your work in this journal}

The Journal of Pain Research is an international, peer-reviewed, open access, online journal that welcomes laboratory and clinical findings in the fields of pain research and the prevention and management of pain. Original research, reviews, symposium reports, hypothesis formation and commentaries are all considered for publication.

\section{Dovepress}

The manuscript management system is completely online and includes a very quick and fair peer-review system, which is all easy to use. Visit http://www.dovepress.com/testimonials.php to read real quotes from published authors. 